\title{
Of Pongo, palms and perceptions: a multidisciplinary assessment of Bornean orang-utans Pongo pygmaeus in an oil palm context
}

\author{
Marc Ancrenaz, Felicity Oram, Laurentius Ambu, Isabelle Lackman \\ Eddie Ahmad, Hamisah Elahan, Harjinder Kler \\ Nicola K. A Bram and Erik MeijaArd
}

\begin{abstract}
The oil palm industry is blamed for the demise of iconic species such as the orang-utan Pongo pygmaeus in Borneo but production of, and demand for, this commodity continue to expand. Therefore, a better understanding of how the orang-utan is adapting to human-transformed environments is crucial for conserving the species. Results from a combination of repeated ground transects, aerial presence/absence surveys, and interviews of workers in mature plantations of the lower Kinabatangan River floodplain (eastern Sabah) provide an overall picture of the current status of orang-utans in an established agroindustrial oil palm landscape. Our results show that orangutans disperse into mature plantations, use oil palm trees for nesting, and feed on mature fruits. Most oil palm workers report orang-utans of all age-sex classes within the estates but fail to report any negative effect of the animals on productivity of mature palms $\geq 5$ years. Our surveys also show that orang-utan presence in the mature oil palm landscape is correlated with proximity to natural forest patches. These results suggest that forest patches, even when small, fragmented and degraded, are required to sustain the species in human-transformed landscapes. Homogenous oil palm plantations are incompatible with viable populations of orang-utans. The cessation of further forest conversion to agriculture and the enforcement of better management practices are needed to reduce the threat of oil palm development to orang-utan survival.
\end{abstract}

MARC ANCRENAZ ${ }^{*}$ (Corresponding author), Felicity Oram, IsABelle Lackman $^{*}$, Eddie Ahmad, Hamisah Elahan, Harjinder Kler and Nicola K. ABRAM $\$$ HUTAN-Kinabatangan Orang-utan Conservation Programme, Sandakan, Sabah, Malaysia. E-mail marc.ancrenaz@yahoo.com

LAURENTiUs Ambu Sabah Wildlife Department, Kota Kinabalu, Sabah, Malaysia ERIK MeIJAARD Borneo Futures, People and Nature Consulting International, Jakarta, Indonesia, and School of Biological Sciences, University of Queensland, Brisbane, Australia

*Also at: Sabah Wildlife Department, Kota Kinabalu, Sabah, Malaysia $\dagger$ Also at: North England Zoological Society, Chester Zoo, Chester, UK, and Borneo Futures, People and Nature Consulting International, Jakarta, Indonesia \$Also at: Durrell Institute for Conservation and Ecology, School of Anthropology and Conservation, University of Kent, Canterbury, UK, and Living Landscape Alliance, Aldermaston, Reading, UK

Received 27 April 2013. Revision requested 15 July 2013.

Accepted 6 September 2013. First published online zo May 2014.
Keywords Aerial nest surveys, best management practices, Borneo, nest decay rate, oil palm plantation, orang-utan, Pongo pygmaeus

\section{Introduction}

evelopment of oil palm plantations is a major driver in the destruction of wildlife habitat (Gilbert, 2012; Wich et al., 2012), and orang-utans (Pongo spp.) are a focal point of conflict between economic development and environmental conservation (Meijaard et al., 2011a). However, the economic benefit generated by this industry stimulates significant public and political support locally, and industrial expansion is likely to continue (Miettinen et al., 2012). Under current standard practice, industrialscale agriculture has limited compatibility with conservation of tropical wildlife (Koh \& Wilcove, 2008). Although some large protected species have been recorded in oil palm landscapes, such as tigers Panthera tigris in Sumatra (Maddox et al., 2007) and elephants Elephas maximus in Borneo and Sumatra (Brown \& Jacobson, 2005; Estes et al., 2012), it is unlikely that these animals could survive in a pure oil palm landscape in the long term. It is therefore necessary to investigate whether and how the survival prospects of wide-ranging protected and threatened species could be enhanced in these landscapes (Meijaard et al., 2012).

Since 1998 the HUTAN-Kinabatangan Orang-utan Conservation Programme has studied the orang-utan population in the Kinabatangan River floodplain region of eastern Sabah, Malaysian Borneo (Ancrenaz et al., 2004a,b). Given the indirect evidence of orang-utan presence within oil palm plantations (nests, reports from local people), HUTAN and the Sabah Wildlife Department decided to conduct a general assessment of the situation in the oil palm landscape of the Kinabatangan. The majority of the plantations had been established for $>_{5}$ years and were therefore considered mature.

The main objectives of this work were to determine (1) if orang-utan presence in mature plantations was localized or occurred throughout the entire lower Kinabatangan area; (2) if, when and how far the animals penetrated mature oil palm plantations; (3) if the animals used the palms for 


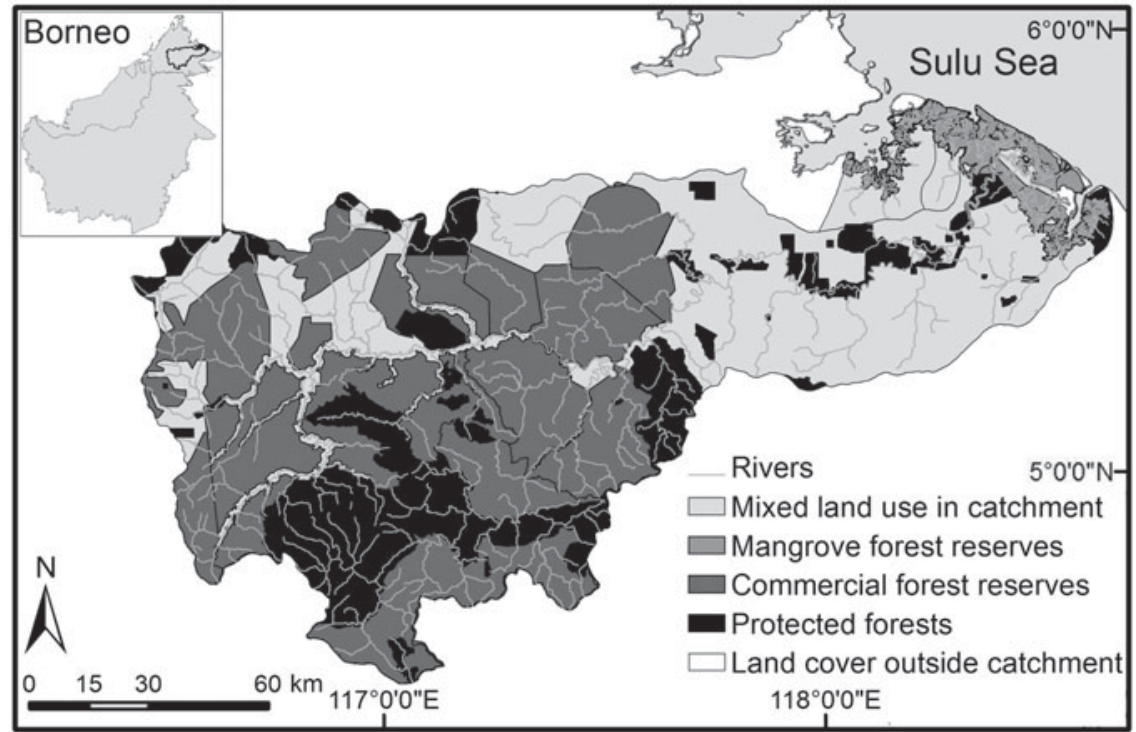

FIG. 1 Forests and non-forest habitats in the Kinabatangan River catchment in eastern Sabah, Malaysian Borneo. nesting, food or travelling; (4) the decay rate of orang-utan sleeping platforms (nests) in oil palm trees; (5) if the animals caused any form of damage to mature palms; and (6) if plantation workers were aware of orang-utans entering oil palm estates. To fulfil objectives 1 and 2 we used aerial surveys to determine orang-utan presence through detection of their nests in the canopy, following established methods (Ancrenaz et al., 2005). Objectives 1, 2, 3 and 4 were also investigated by regular ground monitoring of an oil palm estate bordered by natural forest. We conducted an interview survey of oil palm workers to better understand orang-utan use of oil palm plantations (objectives 5 and 6), as this approach can produce reliable information about presence/absence and people's tolerance of wildlife (Meijaard et al., 2011b).

\section{Study area}

We conducted this research in the lower Kinabatangan River floodplain catchment area $\left(16,800 \mathrm{~km}^{2}\right)$ in eastern Sabah (Fig. 1). Significant changes have occurred since the onset of commercial logging in the early 1960s (McMorrow \& Talip, 2001) and only c. $750 \mathrm{~km}^{2}$ (4\% of the total watershed) of fragmented and degraded forests remain in the lower parts of Kinabatangan. Approximately two-thirds of these lowland forests are protected, comprising the Lower Kinabatangan Wildlife Sanctuary and several Class I Virgin Jungle Forest Reserves. The major land-use matrix outside these forest fragments is composed of extensive oil palm plantations, processing mills, roads, human settlements, small food-crop farms, orchards and patches of degraded forest under private or state ownership.

\section{Methods}

A team of four experienced HUTAN staff conducted two aerial surveys in June 2008 and September 2012 in a small helicopter (Bell 206) flying at low speed (c. 6o knots) and low altitude $(<100 \mathrm{~m}$ above the canopy), following Ancrenaz et al. (2005). We aimed to record the location of small isolated patches of non-protected forest within the oil palm estates and to detect if orang-utan nests were present in these patches. For every forest patch identified during the flights we recorded the following information: (1) location (with a global positioning system); (2) approximate size in four classes: very small ( $<5$ trees), small ( $>_{5}$ trees and $<_{1} \mathrm{ha}$ ), medium $\left(>_{1}\right.$ ha but $\left.<_{10} \mathrm{ha}\right)$, large ( $>10 \mathrm{ha}$ ); (3) stage of degradation of the forest (based on a combination of visual information about canopy closeness, presence of large emergent trees, presence of invasive climbers, and signs of human activity, following Ancrenaz et al., 2005); (4) number of orang-utan nests visible (six classes: none; single, 1 nest; very few, $1-5$ nests; few, 5-10 nests; medium, 10-20 nests; many, $>20$ nests). Because of the small size of the forest patches it was impossible to derive abundance estimates from aerial surveys, and therefore we only assigned presence/absence.

Following several reports of orang-utan sightings in an oil palm estate established in the early 2000 s close to the village of Sukau-PPMS (95 houses and c. 600 people) we established five line-transects (300-800 $\mathrm{m}$, total length $2,850 \mathrm{~m}$ ) within this estate. Inter-transect distance was c. $500 \mathrm{~m}$ (Fig. 2). During February 2011-October 2012 the same team surveyed the five transects for sign of oil palm use by orang-utans. Surveys were carried out every 10 days during February-August 2011 ( $\mathrm{n}=24$ visits) and then twice per month $(\mathrm{n}=22$ visits, with no visits conducted in 

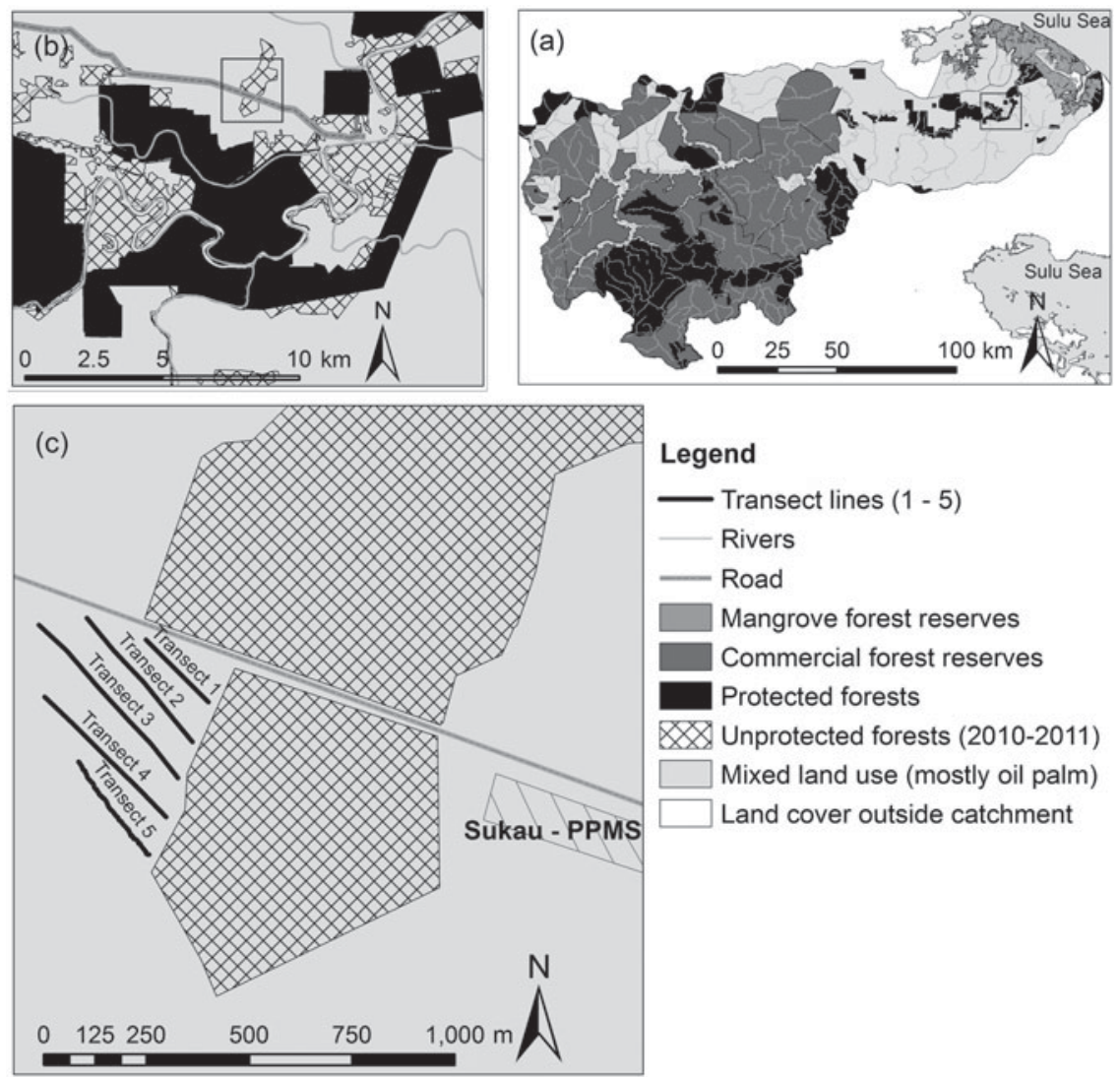

Legend

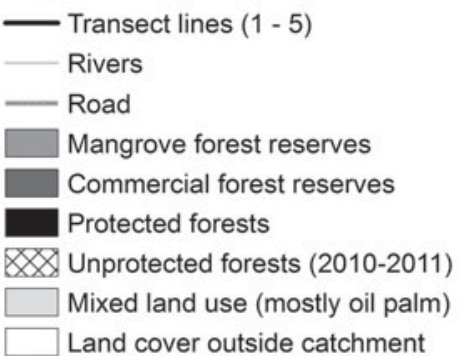

December 2011 or January 2012 because of widespread flooding). For each survey, three lines of palms were assessed on each side of the transect baseline (c. 1,700 palms). Sign left by orang-utans included nests, broken or bent leaves, and partially eaten fruits. As it was not possible to determine if damage was caused by one orang-utan or more, or in one or more forays, damage results are descriptive rather than quantifiable. Fifteen isolated nonpalm trees (mostly Anthocephalus chinensis) that were standing near the transects and within the oil palm estate were also monitored.

Orang-utan nests in palm trees were monitored following Ancrenaz et al. (2004a) to determine their decay rate. A nest was included in our results only if we witnessed its construction $(n=2)$ or detected a strong smell of urine or faeces under the nest $(n=10)$, indicating that it was not more than 1 or 2 nights old (Ancrenaz et al., 2004a).

We conducted a separate experiment to assess the effect of nest-building and leaf destruction on fruit productivity by selecting three oil palm trees with a minimum of five leaves recently damaged by orang-utans for nesting or feeding. As a control we included the five nearest palms without any orang-utan damage $(n=15)$. Once per month we counted the number of fruit bunches still hanging from the palms and those that had already been harvested (indicated by the number of cut stems visible on the palm). We then compared the results for damaged and non-damaged plants, using a $t$-test in SPSS v. 14.0 (SPSS, Chicago, USA).

During September-November 2011 and June-July 2012 we conducted interview surveys to collect information about the use of oil palm plantations by orang-utans and to document the general perception of orang-utans among oil palm workers in the lower Kinabatangan, following similar protocols and recommendations to Meijaard et al. (2011b). The questionnaire was specifically targeted at workers who spend most of their time within the oil palm landscape itself. A letter of consent issued by the Director of the Sabah Wildlife Department was presented to all estate managers, and an introductory text was read to all survey participants, explaining the objectives of the interviews. The identity of respondents was not recorded, to ensure anonymity and to reduce the likelihood of biased results. The questionnaire comprised a mix of 48 open-ended and closed (single answer) questions in Malay. Eleven questions established the basic demographics of the respondents (age, sex, type of work, country of origin, and how long they had lived in the area). Respondents' reliability was then assessed by presenting photographs of eight animals known to be found in the local landscape. People who correctly identified orang-utans and did not misidentify monkeys as orangutans were considered reliable. Only these interviews were used in the analysis; all others were discarded. We asked 23 questions about orang-utan sightings (location, time, 


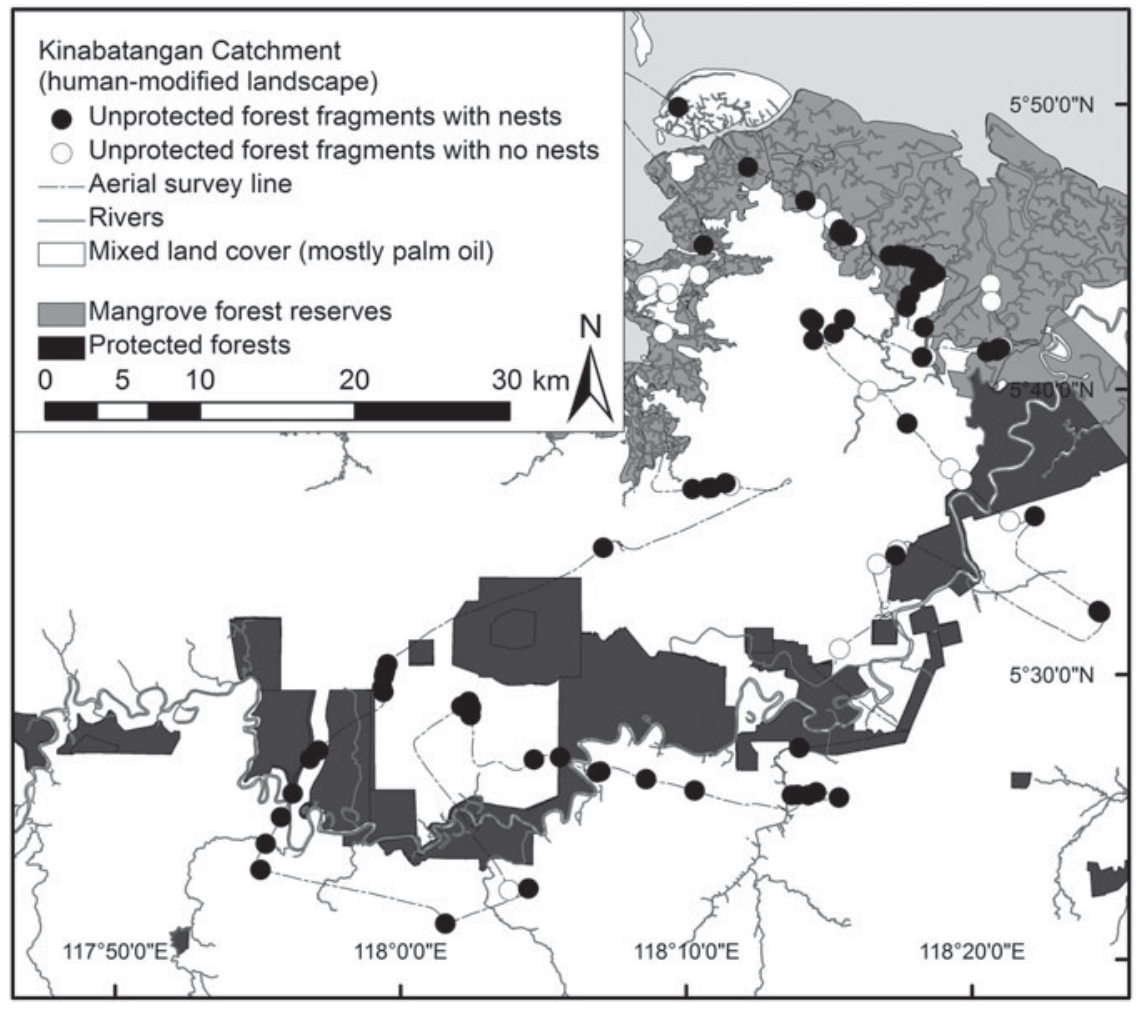

Fig. 3 Locations of orang-utan Pongo pygmaeus nests in non-protected forest patches, identified during a 2012 aerial survey of the lower Kinabatangan catchment. number and description of individuals, activities) and 11 questions on general perceptions of orang-utans. We interviewed 560 plantation field workers from 12 commercial oil palm estates (mean 2,500 ha planted), three smallholders and one village bordering a protected forest.

\section{Results}

The 2008 aerial surveys revealed the presence of $>100$ orang-utan nests in the mangrove area located between the sea and newly established plantations further inland (Fig. 3), even though mangroves are generally not considered to be orang-utan habitat (Rijksen \& Meijaard, 1999). Some of these nests were located in nipah palms Nypa fruticans and others were observed in taller trees (Rhizophora sp., Bruguiera sp., Intsia palembanica). Further towards the interior, away from the mangrove area, we recorded 32 small forest patches that contained orang-utan nests $(1-30 ;>120$ nests in total). These patches ranged in size from a single tree to c. 100 ha, and each patch was completely surrounded by oil palm plantations. During the flight we observed that most of these forest patches were located on ground unsuitable for agriculture (limestone, steep slopes, quarries, swamps). All were degraded, without a closed tree canopy, and invaded by pioneer trees, climbers and creepers. We repeated the aerial survey in 2012. Nests were still detected in most mangroves, except in the north-western part of the mangrove forest reserves that had recently been converted to oil palm monoculture (Fig. 3). Of the 32 non-mangrove forest patches identified in 2008 , only 15 patches were still standing in 2012. Fourteen patches had been converted to oil palm plantations and three patches were in the process of being converted. We identified c. 60 nests in 11 of the remaining forest patches ( $75 \%$ of all forest patches identified during our flight).

The 1,700 palms and 15 non-palm trees included in the regular ground monitoring were checked during 46 surveys throughout the study period. To prevent elephants from entering the estate, one plantation owner had cleared an area along the fence line and created a deep dry trench, 2-5 $\mathrm{m}$ wide, separating the estate from the forest in late July 2012. No orang-utan sign was detected during AugustNovember 2012 in this plantation and only data collected before July 2012 were included in the final analysis $(n=42$ point checks).

A total of 36 orang-utan nests were recorded in palm trees (representing $0.05 \%$ of the total number of palms monitored during the 42 surveys) and four nests in non-palm trees (c. $0.6 \%)$. Orang-utans use the central part of the palm to build their nests, creating a platform of broken leaves to support the inner part of the nest, and bending leaves at the periphery. Bent leaves unfold after a few days or weeks, depending on weather conditions (wind, rain), with no obvious coloration changes. Broken leaves begin to dry after a few weeks and can remain visible for several months in some cases (Plate 1). The mean decay rate was 97.1 \pm SD 52.1 days ( $\mathrm{n}=12$ nests), with one outlier lasting up to 242 days. 


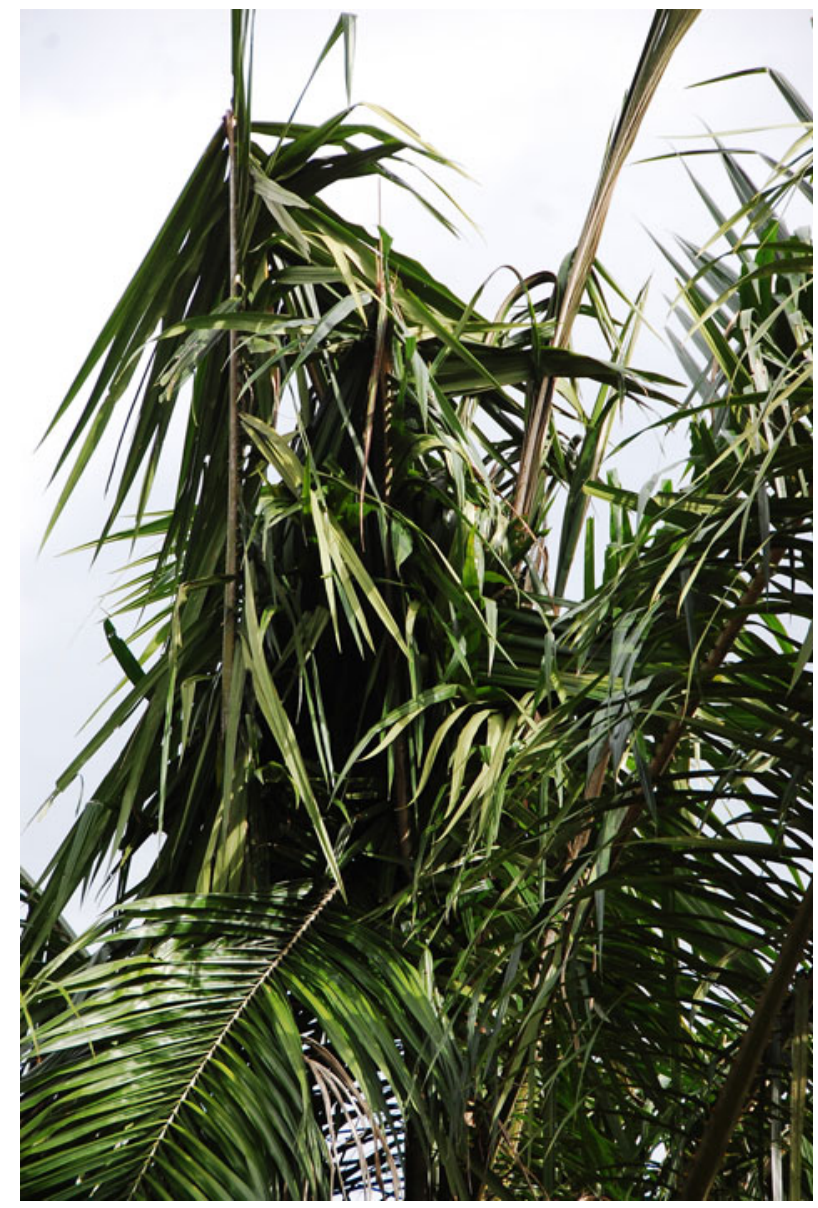

Plate 1 Orang-utan nest in a mature palm tree.

After removing the outlier the mean decay time was $83.9 \pm$ SD 26.0 days $(n=11)$. The majority of nests were located close to a forest edge or to a patch of trees (mean distance $62 \pm \mathrm{SD} 41 \mathrm{~m}$ ), the furthest distance being only $150 \mathrm{~m}$. Leaves broken or damaged by orang-utans as a result of travelling or feeding activities were recorded in 41 palms (0.057\% of our total sample size). This type of damage was recorded up to $400 \mathrm{~m}$ away from the edge of a patch of trees. Appearance of new nests and damage to palms were highly correlated (Pearson's $r=0.835, \mathrm{P}<0.001$ ). Most leaf damage and establishment of new nests occurred in the first months of the year but a $t$-test comparing the number of events in February-June to July-November did not indicate any significant temporal differences $(t=1.52$, $\mathrm{df}=10.27, \mathrm{P}=0.159)$. A $t$-test comparing the mean number of fruit bunches produced by damaged trees $(n=42$, mean $=6.6 \pm$ SE $0.38,95 \%$ CI 5.82-7.37) and non-damaged trees $(n=210$, mean $=7.33 \pm$ SE $0.245,95 \%$ CI 6.84-7.83 $)$ did not show a statistically significant difference between the two samples $(F=0.562, t=0.311, \mathrm{P}=0.757)$.

Of 560 interviewees, 214 reported seeing an orang-utan at least once. Of these 214 respondents, 156 (27.8\% of the general total) were considered reliable. Of the 156 reliable respondents, 141 (90.5\%; mean age $31.4 \pm$ SD 10.3 years) reported having seen an orang-utan within the local oil palm plantation or its immediate surroundings. Ninety-two informants $(65.2 \%)$ reported an orang-utan sighting within the previous 2 years and $103(73 \%)$ reported a sighting within the previous 3 years, indicating that most of the sightings were relatively recent although most palm estates had been established for $>25$ years. Forty-two respondents (29.8\%) reported seeing an orang-utan within homogenous oil palms. Seventeen people $(40 \%$ of those that reported sightings within contiguous oil palm) reported sightings of animals in the oil palm trees, with the remainder reporting sightings of animals walking or running on the ground (two orang-utans were reported crossing the main paved road leading to Sukau). Sightings indicate that all sexage classes are present within this landscape: 55 reliable reports of a single non-flanged individual of unknown sex, 12 of adult females with a clinging baby, three of an adult female with an accompanying juvenile, and 14 of a flanged male. The majority of workers (97 respondents; 68.8\%) said that orang-utans caused no disturbance in mature palm trees except for breaking leaves, which was considered of little or no consequence to palm productivity, reinforcing the findings of our own experiment.

\section{Discussion}

Aerial and ground surveys show orang-utan nests in forest patches and isolated trees throughout the entire oil palm matrix of the lower Kinabatangan floodplain, as well as in oil and nipah palms. Although our regular ground monitoring suggests that orang-utans preferentially select non-oil palm trees for nesting within a plantation, oil palms are also used for this purpose. Orang-utan nests built in oil palms are similar in form and shape to those built in nipah palms in mangrove areas (MA, pers. obs.) or chimpanzee nests in native wild oil palm trees in Guinea Bissau (Sousa et al., 2011). The nest decay rate in oil palms is short compared to other tree species (Ancrenaz et al., 2004a). Orang-utans also use oil palm as a food source, consuming young shoots and ripe fruits picked from bunches on the ground or on the palm (we witnessed this behaviour directly on one occasion). Undigested oil palm fruits were also detected in several orang-utan faeces samples (KOCP, unpubl. data). Our results also indicate that the destruction of leaves by orang-utans in mature palms (i.e. $>5$ years old) has no effect on fruit productivity. In contrast, a high rate of damage caused by orang-utans to young palms $<_{4-5}$ years of age has been recorded in areas of new land conversion (Yuwono et al., 2007).

Circa $90 \%$ of orang-utan sign identified within oil palm plantation was found within $50 \mathrm{~m}$ of forest patches, suggesting orang-utan distribution within an oil palm estate depends on the presence of natural forests and non-palm trees. Although orang-utans can move from palm to palm 
arboreally, they often walk on the ground to move through an oil palm plantation or to cross roads and open areas quickly when disturbed by people. Moving on the ground is quieter than moving through the palm fronds arboreally so this may be an adaptive response to avoid detection (authors, pers. obs.). But increased terrestrial locomotion in a human-made vegetation matrix may increase conflict with people, susceptibility to hunting and exposure to new diseases (Loken et al., 2013; Ancrenaz et al., 2014).

Our unexpected findings of use of oil palm areas by orang-utans are reinforced by the relatively high encounter rate between oil palm workers and orang-utans within this agro-industrial landscape. The percentage of reliable respondents who reported sightings in the oil palm plantation landscape (90.2\%) is significantly higher than the percentage of local people who, during a general interview study, reported having seen wild orang-utans in the forests of Kalimantan (42\%; Meijaard et al., 2011a,b). Orang-utans appear more resilient to habitat changes than was originally thought: apparently viable populations are found in commercial forests exploited using reducedimpact logging practices in Sabah (Ancrenaz et al., 2010); significant numbers of individuals are found in acacia plantations in East Kalimantan (Meijaard et al., 2010); and stable groups have been living in a mosaic of mixed agriculture and forest in Sumatra for $>20$ years (CampbellSmith et al., 2011a,b).

However, these results do not suggest that agroindustrial environments can sustain orang-utans. Longterm study is needed to monitor the changes in the number of orang-utan sightings with the age of the plantation or the time since forest clearance, and to document whether this landscape can accommodate orang-utans and provide safe passage for dispersal between forest fragments.

In the early 1960 s the lower Kinabatangan floodplain was covered with forests and the overall orang-utan density was at least 0.5 per $\mathrm{km}^{2}$ (Yoshiba, 1964). Based on this conservative estimate there were $>4,000$ orang-utans in the forests of the lower Kinabatangan (c. $8,000 \mathrm{~km}^{2}$ ) before their conversion to agriculture. Recent estimates indicate that there are c. 800 orang-utans remaining in the lower Kinabatangan (Ancrenaz, unpubl. data), and genetic analysis shows that this population has declined by $>95 \%$ in the last 100 years (Goossens et al., 2006). These results show that converting forests occupied by orang-utans to oil palm plantations is a major threat to orang-utan survival; the majority of the resident orang-utans are either killed outright (Wich et al., 2012) or starve; neither young oil palm shoots nor mature oil palm provides a sufficient food source for such a large mammal. We can therefore assume that most orang-utans sighted in the plantations today belong to the original Kinabatangan meta-population, which is now fragmented as a result of forest conversion to agriculture. These animals may have lost their original home territory when the forest was destroyed or they may be dispersing between fragmented forest patches in search of food or mating opportunities. Long-term monitoring of orang-utan presence and distribution is needed to ascertain if these animals are part of a declining remnant population or if they can be self-sustaining within the agro-industrial/degraded forest matrix. This study indicates that the presence of small natural patches is essential for orang-utan survival but further study is needed to establish how conservation of this nationally and internationally protected species can be assured within a mixed-use landscape.

There are already relevant recommendations for minimizing the negative effect of oil palm development on orang-utan survival (RSPO, 2007; Dennis et al., 2010). Our results emphasize the value of patches of forest within an oil palm landscape for orang-utan conservation, irrespective of their size and degree of degradation. This must be recognized and acknowledged by government planners and policymakers, the scientific community, the private sector and all land-users. Forest patches and corridors must be identified, marked and set aside before any new development takes place, with a view to maintaining ecosystem functionality and meta-populations of wildlife (Koh \& Wilcove, 2008; McShea et al., 2009; SWD, 2012). These patches should not be converted but incorporated in land-use plans as ecological set-asides, and appropriately managed. Planting non-palm trees throughout an agro-industrial oil palm landscape will increase food opportunities for wildlife and create possible nesting sites for orang-utans. Trenches and strips of bare land seem to deter orang-utans from entering oil palm plantations and could physically separate plantations from forests inhabited by orang-utans, to mitigate conflicts when plantations are newly established. When palms become more mature these trenches could be bridged to allow orang-utans to move across the mature oil palm landscape. Orang-utan survival in highly modified landscapes is dependent on human tolerance towards them (Wich et al., 2012), and hunting will threaten the survival of these populations (Marshall et al., 2009). A zero-tolerance policy on the killing of orang-utans and other harmful acts needs to be strictly enforced at all management levels. Finally, thorough and regular monitoring of orang-utan presence and of the condition of forest patches needs to be implemented in all oil palm estates within the orang-utan range. All sightings of orang-utans and other protected wildlife should be reported by oil palm workers to their team leaders and a proper flow of information needs to be established between field operation management and wildlife authorities.

\section{Acknowledgements}

We thank the Sabah Wildlife Department, the Economic Planning Unit and the Sabah Biodiversity Council for 
permission to work in Sabah; the 50 HUTAN field research assistants for their dedication to biodiversity conservation in Sabah; the staff of the Wildlife and Forestry Department and all who have supported our work in Sabah; Rajak, Azli, Herman, Daisah, Rahadi, Rusiman, Waslee, Hartiman and Faisal of the HUTAN/KOCP_Orang-utan Research Team; Haslan and Shernytta; all informants who agreed to respond to our questions; Encik Haji Montoi for granting us permission to use his estate for this study; and the anonymous reviewers of this article. This study was supported by Zoo Basel, the ARCUS Foundation, the U.S. Fish \& Wildlife Service, and all HUTAN supporters.

\section{References}

Ancrenaz, M., Ambu, L., Sunjoto, I., Ahmad, E., Manokaran, K., MeijaArd, E. \& Lackman, I. (2010) Recent surveys in the forests of Ulu Segama Malua, Sabah, Malaysia, show that orang-utans (Pongo pygmaeus morio) can be maintained in slightly logged forests. PLoS ONE, 5(7), e11510. Http://dx.doi.org/10.1371/journal.pone.0011510 [accessed 22 March 2014].

Ancrenaz, M., Calaque, R. \& Lackman-Ancrenaz, I. (2004a) Orangutan nesting behavior in disturbed forest of Sabah, Malaysia: implications for nest census. International Journal of Primatology, 25, 983-1000.

Ancrenaz, M., Gimenez, O., Ambu, L., Ancrenaz, K., Andau, P., Goossens, B. et al. (2005) Aerial surveys give new estimates for orangutans in Sabah, Malaysia. PLoS Biology, 3(1), e3. Http://dx.doi. org/10.1371/journal.pbio.0030003 [accessed 22 March 2014].

Ancrenaz, M., Goossens, B., Gimenez, O., Sawang, A. \& Lackman-Ancrenaz, I. (2004b) Determination of ape distribution and population size with ground and aerial surveys: a case study with orang-utans in lower Kinabatangan, Sabah, Malaysia. Animal Conservation, 7, 375-385.

Ancrenaz, M., Sollmann, R., Meijaard, E., Hearn, A.J., Ross, J., SAmejima, H. et al. (2014) Coming down from the trees: is terrestrial activity in orangutans natural or disturbance-driven? Nature Scientific Reports, 4, 1-4. Http://dx.doi.org/10.1038/srep04024 [accessed 7 April 2014].

Brown, E. \& Jacobson, M.F. (2005) Cruel Oil: How Palm Oil Harms Health, Rainforest and Wildlife. Center for Science in the Public Interest, Washington, DC, USA.

Campbell-Smith, G., Campbell-Smith, M., Singleton, I. \& Linkie, M. (2011a) Apes in space: saving an imperilled orangutan population in Sumatra. PLoS ONE, 6(2), e17210. Http://dx.doi.org/10. 1371/journal.pone.0017210 [accessed 22 March 2014].

Campbell-Smith, G., Campbell-Smith, M., Singleton, I. \& Linkie, M. (2011b) Raiders of the lost bark: orangutan foraging strategies in a degraded landscape. PLoS ONE, 6(6), e20962. Http://dx.doi.org/10.1371/journal.pone.0020962 [accessed 22 March 2014].

Dennis, R., Grant, A., Hadiprakarsa, Y., Hartman, P., Kitchener, D.J., Lamrock, T. et al. (2010) Best Practices for Orangutan Conservation-Oil Palm Concessions. Orangutan Conservation Services Program, USAID, Jakarta, Indonesia.

Estes, J., Othman, N., Ismail, S., Ancrenaz, M., Goossens, B., АмвU, L. et al. (2012) Quantity and configuration of available elephant habitat and related conservation concerns in the Lower Kinabatangan floodplain of Sabah, Malaysia. PLoS ONE, 7(10), e44601. Http://dx.doi.org/10.1371/journal.pone.0044601 [accessed 22 March 2014].

Gilbert, D. (2012) Truth and Consequences: Palm Oil Plantations Push Unique Orangutan Population to Brink of Extinction.

Rainforest Action Network, San Francisco, USA.

Goossens, B., Chikhi, L., Ancrenaz, M., LaCkman-Ancrenaz, I., ANDAu, P. \& Bruford, M.W. (2006) Genetic signature of anthropogenic population collapse in orang-utans. PLoS Biology, 4(2), e25. Http://dx.doi.org/10.1371/journal.pbio.0040025 [accessed 22 March 2014].

KoH, L.P. \& W ILCOVE, D.S. (2008) Is oil palm agriculture really destroying tropical biodiversity? Conservation Letters, 1, 60-64.

Loken, B., Spehar, S. \& Rayadin, Y. (2013) Terrestriality in the Bornean orang-utan (Pongo pygmaeus morio) and implications for their ecology and conservation. American Journal of Primatology, 75, 1129-1138.

Maddox, T., Priatna, D., Gemita, E. \& Salampessy, A. (2007) The Conservation of Tigers and other Wildife in Oil Palm Plantations, Jambi Province, Sumatra, Indonesia. Zoological Society of London Conservation Report No. 7. The Zoological Society of London, London, UK.

Marshall, A.J., Lacy, R., Ancrenaz, M., Byers, O., Husson, S.J., Leighton, M. et al. (2009) Orangutan population biology, life history and conservation. In Orangutans: Geographic Variation in Behavioral Ecology and Conservation (eds S.A. Wich, S.S. Utami Atmoko, T. Mitra Setia \& C.P. van Schaik), pp. 311-325. Oxford University Press, Oxford, UK.

McMorrow, J. \& Talip, M.A. (2001) Decline of forest area in Sabah, Malaysia: relationship to state policies, land code and land capability. Global Environmental Change, 11, 217-230.

McShea, W.J., Stemart, C., Peterson, L., Erb, P., Stuebing, R. \& GimAN, B. (2009) The importance of secondary forest blocks for terrestrial mammals within an Acacia/secondary forest matrix in Sarawak, Malaysia. Biological Conservation, 142, 3108-3119.

Meijaard, E., Albar, G., Nardiyono, Rayadin, Y., Ancrenaz, M. \& SPEHAR, S. (2010) Unexpected ecological resilience in Bornean orangutans and implications for pulp and paper plantation management. PLoS ONE, 5(9), e12813. Http://dx.doi.org/10.1371/ journal.pone.0012813 [accessed 23 March 2014].

Meijaard, E., Buchori, D., Hadiprakarsa, Y., UtamiAтмоко, S.S., Nurcahyo, A., Tiu, A. et al. (2011a) Quantifying killing of orangutans and human-orangutan conflict in Kalimantan, Indonesia. PLoS ONE, 6(11), e27491. Http://dx.doi.org/10.1371/journal.pone.0027491 [accessed 23 March 2014].

Meijaard, E., Mengersen, K., Buchori, D., Nurcahyo, A., Ancrenaz, M., Wich, S. et al. (2011b) Why don't we ask? A complementary method for assessing the status of great apes. PLoS ONE, 6(3), e18008. Http://dx.doi.org/10.1371/journal.pone. 0018008 [accessed 23 March 2014].

Meijaard, E., Wich, S., Ancrenaz, M. \& Marshall, A.J. (2012) Not by science alone: Why orangutan conservationists must think outside the box. Annals of the New York Academy of Sciences, 1249, $29-44$.

Miettinen, J., Hooijer, A., Tollenaar, D., Page, S., Malins, C., Vernimmen, R. et al. (2012) Historical Analysis and Projection of Oil Palm Plantation Expansion on Peatland in Southeast Asia. International Council on Clean Transportation, Washington, DC, USA.

Rijksen, H.D. \& Meijand, E. (1999) Our Vanishing Relative. The Status of Wild Orang-utans at the Close of the Twentieth Century. Kluwer Academic Publishers, Dordrecht, The Netherlands. 
RSPO (Roundtable on Sustainable Palm Oil) (2007) RSPO Principles and Criteria for Sustainable Palm Oil Production. Http:// www.rspo.org/sites/default/files/RSPO\%2oPrinciples\%20\&\% 20Criteria.pdf [accessed 23 March 2014].

Sousa, J., Barata, A.V., Sousa, C., Casanova, C.C.N. \& Vicente, L. (2011) Chimpanzee oil-palm use in Southern Cantanhez National Park, Guinea-Bissau. American Journal of Primatology, 73, 485-497.

SWD (Sabah Wildlife Department) (2012) Sabah Wildlife Department Orangutan Action Plan 2012-2016. Kota Kinabalu, Sabah, Malaysia.

Wich, S.A., Gaveau, D., Abram, N., Ancrenaz, M., Baccini, A., Brend, S. et al. (2012) Understanding the impacts of land-use policies on a threatened species: is there a future for the Bornean orangutan? PLoS ONE, 7(11), e49142. Http://dx.doi.org/10.1371/journal. pone.0049142 [accessed 23 March 2014].

Yoshib A, K. (1964) Report of the preliminary survey on the orang-utan in North Borneo. Primates, 5, 11-26.

Yuwono, E.H., Susanto, P., Saleh, C., Andayani, N., Prasetyo, D. \& Aтмокo, S.S.U. (2007) Guidelines for Better Management Practices on Avoidance, Mitigation and Management of Human-Orangutan Conflict in and around Oil Palm Plantations. WWF-Indonesia, Jakarta, Indonesia.

\section{Biographical sketches}

For 15 years orang-utan conservation in Sabah has been led by the HUTAN-Kinabatangan Orang-utan Conservation Programme (KOCP), the Sabah Wildlife Department and other partners active in Kinabatangan and throughout the state. MARC ANCRENAZ and ISABELLE LACKMAN established HUTAN/KOCP in 1998 and have promoted orang-utan conservation at the landscape level throughout Sabah since then. Felicity Oram, Eddie Ahmad and Hamisah ELAHAN are part of the KOCP team that studies wild habituated orang-utans at the KOCP intensive study site and in surrounding oil palm estates. LaURENTiUs Ambu is the director of the Sabah Wildlife Department and oversees the Lower Kinabatangan Wildlife Sanctuary. Harjinder Kler and Nicola Abram are involved in the development of a strategic conservation plan for orang-utans in the agro-industrial landscape of the Kinabatangan. Erik Meija ard has been working on orang-utan and general conservation issues in Borneo for many years. 